\title{
Special aspects of attic floor warming in historic buildings
}

\author{
Vera Murgul ${ }^{1,2, *}$ \\ ${ }^{1}$ Moscow State University of Civil Engineering, Yaroslavskoe shosse, 26, Moscow, 129337, Russia \\ ${ }^{2}$ Peter the Great St. Petersburg Polytechnic University, Politechnicheskaya st., 29, St. Petersburg, \\ 195251, Russia
}

\begin{abstract}
This article containsreasoningof the heat transfer performance uniformity factor determinationfor attic floorsof historic residential buildings while energy effective modifying buildings. The numeral value of this heat transfer performance uniformity factor for the wooden attic floor structure was founddurung investigation. It was estimated that there was no moisture condensation in the wooden attic floor structure.
\end{abstract}

\section{Introduction}

Energy efficient reconstruction of historic buildings is a peculiar challenge because of being connected with the necessity of highest possible preserving of historical engineering structures and valuable historic interiors. Warming of enclosure structures of historic buildings became necessary on a regular basis only in the latest two decades because of standards tightening for building energy usage.

It influenced on lots of scientific researches dedicated to this problem [1-10]. This scientific research is dedicated to special aspects of attic floor warming in historic buildings.

\section{Materials and methods}

The reconstruction of wooden attic floor with historical ceiling preserving. Warming of attic floors is a traditional measure being part of energy effective modifying of historic residential buildings. According to nature surveys, wooden beams being part of attic floor structure are often in satisfactory state and can be maintained.

The solution of wooden attic floor reconstruction with existing historical ceiling preserving and thermal insulation replacement are described below. Structure solution of the attic floor is shown on Figure 1.

\footnotetext{
"Corresponding author: vera.murgul@mail.ru
} 


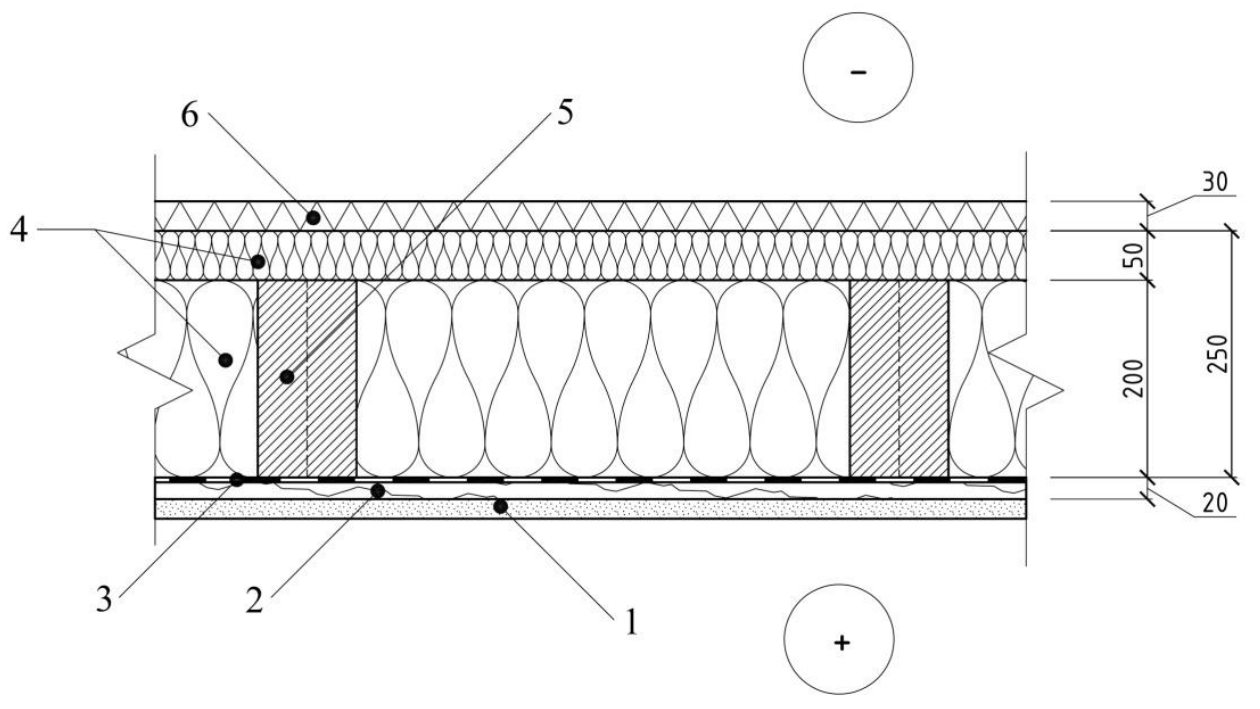

Fig. 1. Structure solution of the wooden attic floor, where 1 - plastering; 2 - sheathing of boards; 3 vapor insulation; 4- thermal insulation PAROC eXtra; 5 - wooden floor beams $100 \times 200 \mathrm{~mm}$ with $600 \mathrm{~mm}$ pitch; 6 - thermal insulation PAROC WAS 35t.

\section{Results}

Determination of the heat transfer performance uniformity factor for attic floors of historic buildings. The thermotechnical calculation of the determined structure was executed in $\mathrm{Kiev}$ climate conditions. Inside air temperature $+20^{\circ} \mathrm{C}$, outside air temperature $-22{ }^{\circ} \mathrm{C}$ were taken into account for the calculation. Reducedthermalresistancerequiredis $4.95{ }^{\circ} \mathrm{C} / \mathrm{W}$ [11].

According to the calculations, thermal resistance of the thermal insulation over the sheathing is $R_{0}=6.984 \mathrm{~m}^{2} \cdot{ }^{\circ} \mathrm{C} / \mathrm{W}$ and in the cross-section in the middle of the beam is $R_{0}=$ $3.333 \mathrm{~m}^{2} \cdot{ }^{\circ} \mathrm{C} / \mathrm{W}$.

The beams in the floor structure is a thermally conductive inclusions.

The temperature pattern was calculated in the software application "ELCUT" with the design outdoor temperature for the heat transfer performance uniformity factordetermination (Figure 2).

The heat transfer performance uniformity factorris a non-dimension value equaling the ratio of the heat flow through the section of a heterogeneous enclosure structure to the heat flow through the conditional homogenous enclosure structure with the same surface area as the section. During the calculation a value of the heat transfer performance uniformity factorof the enclosure structure was found $(r=0.806)$. The heat transfer performance uniformity factor included the beam influence.

Reduced thermal resistance of the attic floor

$$
R_{o}^{n p}=R_{o} \cdot r, \mathrm{~m}^{2} \cdot{ }^{\circ} \mathrm{C} / \mathrm{W},
$$

Where $R_{o}$ isthermal resistance of the homogeneous enclosure structure, $\mathrm{m}^{2} \cdot{ }^{\circ} \mathrm{C} / \mathrm{W}$

Thermal resistance of the homogeneous enclosure structure 


$$
R_{o}=\frac{1}{\alpha_{s}}+\sum \frac{\delta_{i}}{\lambda_{i}}+\frac{1}{\alpha_{n}}, \mathrm{~m}^{2} \cdot{ }^{\circ} \mathrm{C} / \mathrm{W}
$$

a)

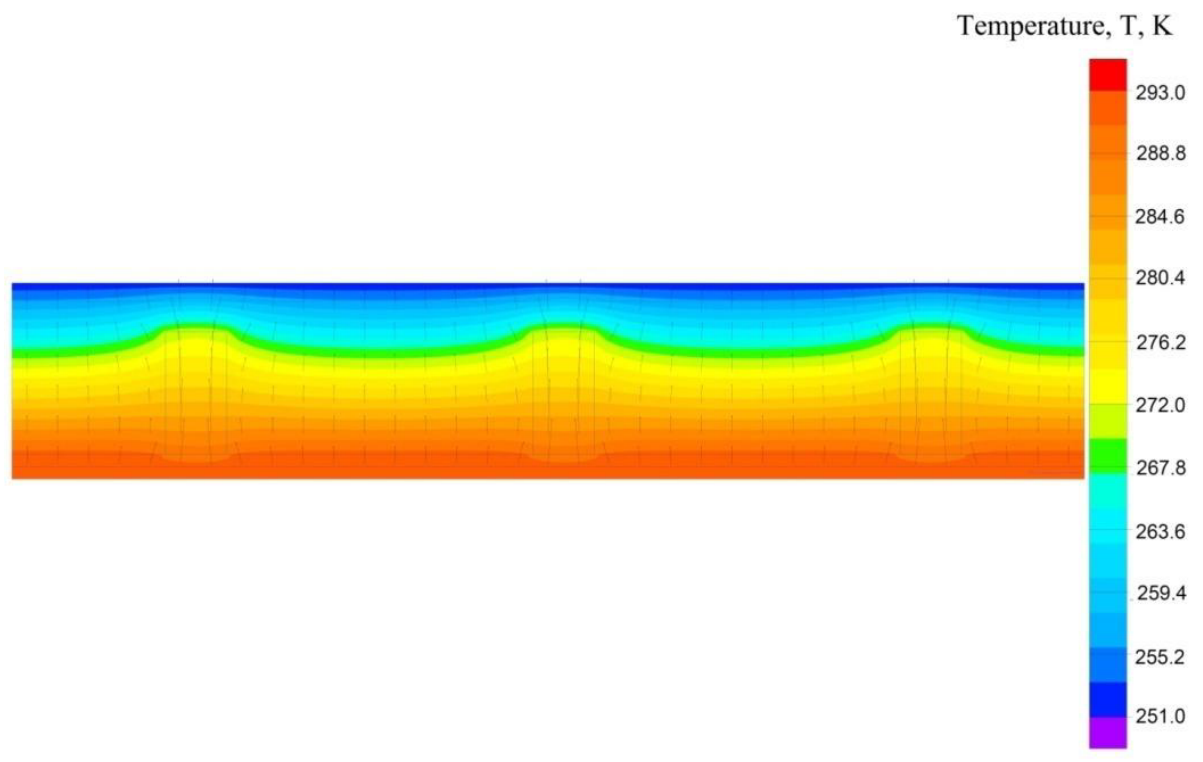

b)

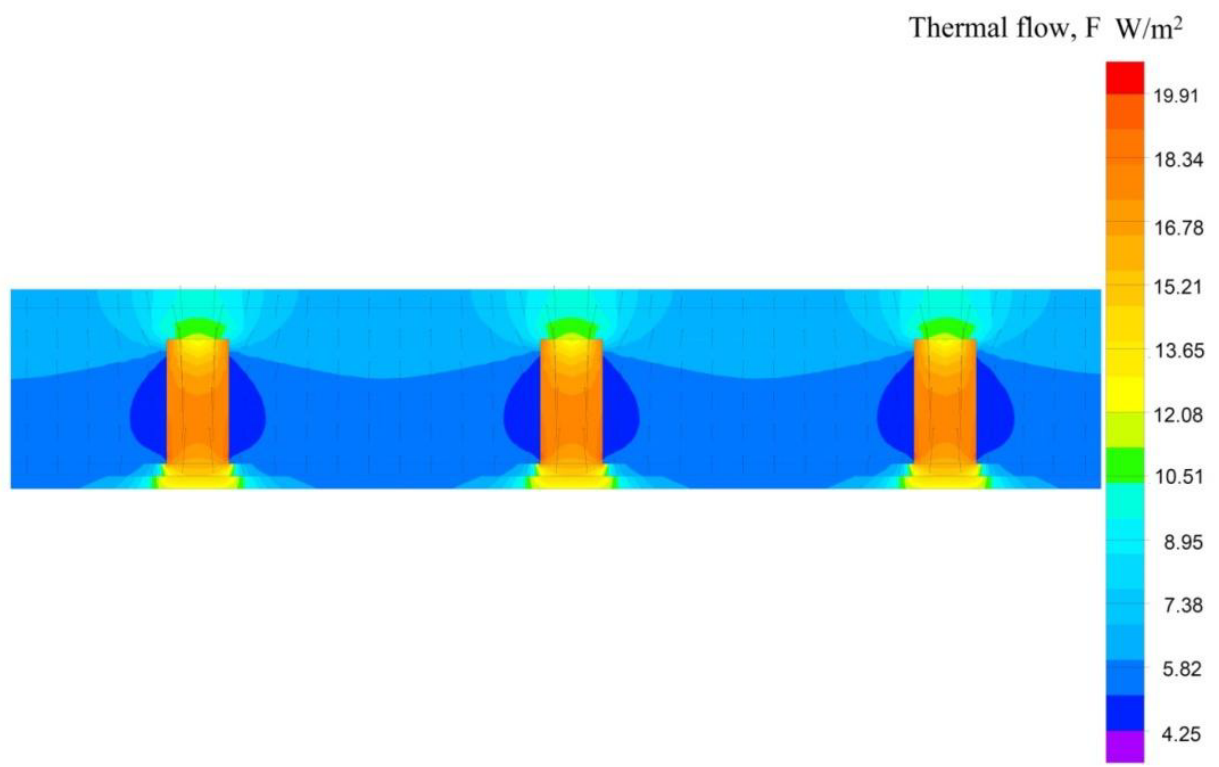

Fig. 2. Temperature pattern (a) and spread of thermal flows (b) in the attic floor structure.

Where $\alpha_{\theta}$ is a heat transfer coefficient of the inner surface of the enclosure structure, $\mathrm{W} /\left(\mathrm{m}^{2} \cdot{ }^{\circ} \mathrm{C}\right) ; \sum \frac{\delta_{i}}{\lambda_{i}}$ is a sum of layer resistances of the enclosure structure $\mathrm{W} /\left(\mathrm{m}^{2} \cdot{ }^{\circ} \mathrm{C}\right) ; \alpha_{u}$ is aheat transfer coefficient of the outer surface of the enclosure structure, $\mathrm{W} /\left(\mathrm{m}^{2} \cdot{ }^{\circ} \mathrm{C}\right)$; 
Reducedthermalresistanceof the studied wooden attic floor $R_{o}^{n p}=6.984 \cdot 0.806=5.629$ $\mathrm{m}^{2} \cdot{ }^{\circ} \mathrm{C} / \mathrm{W}$.

\section{The risk of condensate formation}

Following the calculation of the temperature pattern, the temperature change on the axis of the beam was determined and the scheme of the humidity conditions of the floor structure without vapor barrier was constructed (Figure 3).

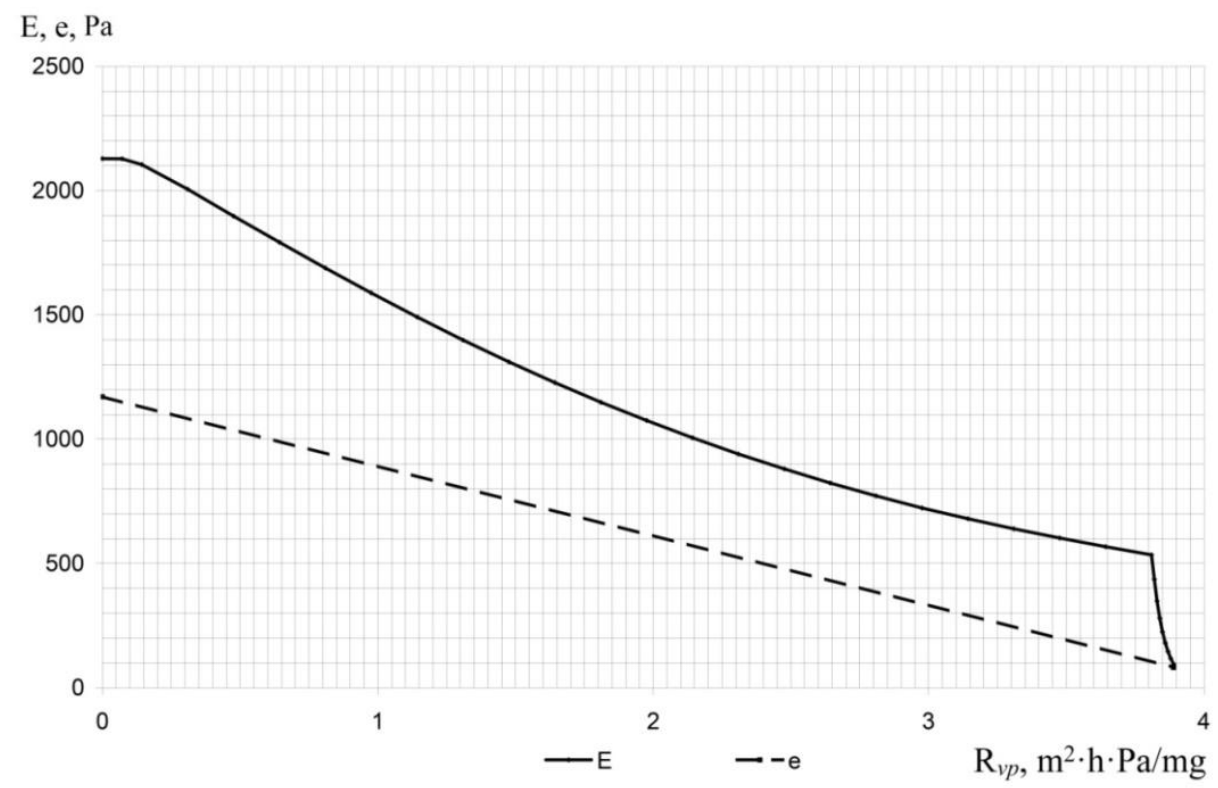

Fig. 3. Scheme of attic floor humidity conditions at the design temperature of outside air $-22^{\circ} \mathrm{C}$ (from left to right - from the inside surface to the outside surface of the floor).

Lines e (the line of partial pressure of saturated steam, $\mathrm{Pa}$ ) and $\mathrm{E}$ (the line of saturated steam pressure change, $\mathrm{Pa}$ ) do not cross at the design temperature of $22{ }^{\circ} \mathrm{C}$, which means that there is no moisture condensation in the attic floor in this case [12]. Thefloorisdrawnonascaleofvaportransmission resistances $\left(\mathrm{R}_{v p}, \mathrm{~m}^{2} \cdot \mathrm{h} \cdot \mathrm{Pa} / \mathrm{mg}\right)$.

\section{Conclusion}

1. Energy efficiency modifying of residential historical buildings should imply the principle of highest possible preserving historical engineering structures of a building.

2. The studied structure solution of the attic floor thermal insulation using modern efficient thermal insulation materials enables to exclude the risk of condensate formation in layers of a wooden floor being preserved.

3. The calculation of the temperature pattern and thermal flows of the floor structure in the software application "ECULT" evidentiated the necessity of the heat transfer performance uniformity factor consideration while executing thermotechnical calculations. The value of the heat transfer performance uniformity factor for the wooden attic floor including beam influence was determined, $r=0.806$. 


\section{References}

1. A.Martínez-Molina, I. Tort-Ausina, S.Cho, J.L.Vivancos, Renewable and Sustainable Energy Reviews 61, 70-85 (2016)

2. C.Cornaro, V.A.Puggioni, R.M.Strollo, Journal of Building Engineering6, 17-28(2016)

3. A. Magrini, G. Franco, Journal of Cultural Heritage 21, 834-841(2016)

4. J.Zagorskas, E.K.Zavadskas, Z.Turskis, M.Burinskienè, A.Blumberga, D. Blumberga, Energy and Buildings 78, 35-42(2014)

5. K.Fabbri, B. Brunetti, Energy Procedia 78, 1281-1286(2015)

6. R. Walker, S.Pavía, Building and Environment 94(1), 155-165 (2015)

7. E.Arumägi, M.Pihlak, T.Kalamees, Energy Procedia 78, 871-876(2015)

8. U. Alev, L. Eskola, E. Arumägi, J. Jokisalo, A. Donarelli, K. Siren, T. Broström, T. Kalamees, Energy and Buildings, 77, 58-66 (2014)

9. G.M.Ageeva, N.V. Marchenko, Energosberezhenie. Energetika. Energoaudit 9, 9-15 (2010)

10. G.G. Farenyuk, Yu.A. Matrosov, Rekonstruktsiyazhitla 9, 20-31(2008)

11. Ukraine Standard DBN V.2.6-31:2006

12. Russian Standard SP 23-101-2004 